\title{
PRODUÇÃO DE AMILASES PELO FUNGO MACROPHOMINA PHASEOLINA
}

\author{
Amylases production for the fungus Macrophomina phaseolina
}

\author{
Lílian Patricia Fernandes ${ }^{1,2}$; Cirano José Ulhoa ${ }^{3}$; Eduardo Ramirez Asquieri ${ }^{4}$; Valdirene \\ Neves Monteiro ${ }^{1,5^{*}}$ \\ ${ }^{1}$ Unidade Universitária de Ciências Exatas e Tecnológicas da Universidade Estadual de Goiás- UnUCET/ UEG. \\ BR 153, Km 98 Campus Henrique Santillo. CEP: 75000-000. Anápolis-GO, Brasil. \\ ${ }^{2}$ Aluna do Curso de Química Industrial \\ ${ }^{3}$ Professor de Bioquímica da Universidade Federal de Goiás. Instituto de Ciências Biológicas-ICB/UFG. Campus \\ Samambaia. CEP: 74001-940. Goiânia-GO, Brasil. \\ ${ }^{4}$ Professor de Bioquímica de Alimentos da Universidade Federal de Goiás. Faculdade de Farmácia-FF/UFG. \\ Praça Universitária s/n. 74605-220. Goiânia-GO, Brasil. \\ ${ }^{5}$ Professora das disciplinas de Bioquímica I e II e Enzimologia.
}

Autor para correspondência e-mail: valdirene.neves@ueg.br

Recebido em 19/03/2007 - Aceito em 22/05/2007

RESUMO: Amilases constituem um grupo de enzimas que possuem ação sobre o amido liberando diversos produtos, incluindo dextrinas e progressivamente pequenos polímeros compostos de unidades de glicose (GUPTA, et al., 2003). Apresentam importantes aplicações biotecnológicas principalmente nas indústrias farmacêutica, têxtil, detergente e alimentícia. Enzimas amilolíticas são produzidas por bactérias, leveduras e fungos. As enzimas amilolíticas mais utilizadas são aquelas produzidas por fungos filamentosos e principalmente as dos gêneros Aspergillus e Rhizopus (PANDEY, et al., 1999 e PANDEY, et al.,2005). Macrophomina phaseolina pertence ao reino Fungi, Phylum Ascomomycota, classe Ascomycetes gênero Macrophomina (GALL, et al.,1980). O fungo Macrophomina phaseolina é um fitopatógeno agente causal da podridão cinzenta do caule, é considerado, pelos danos causados, um dos principais patógenos de sementes de feijão (CHIBA, et al., 2000). Por outro lado, o aspecto de produtor de enzimas de interesse biotecnológico é muito pouco conhecido na avaliação de um benefício que este fungo poderia oferecer aos mais diversos setores industriais.

Neste trabalho objetivou-se avaliar a produção de amilases pelo fungo Macrophomina phaseolina em fontes de carbono convencionais e não convencionais e, sobretudo avaliar o potencial de M.phaseolina na produção de enzimas de interesse biotecnológico e sua inclusão de mais uma alternativa na utilização de fungos para a produção de moléculas de interesse industrial. Os resultados mostram boas atividades específicas de amilases com atividades dextrinizantes e sacarificantes em fontes de carbono como amido, farinha de arroz e farinha de semente de jaca. Foram ainda analisados os perfis de proteínas totais em gel de poliacrilamida e atividade amilolítica em gel de poliacrilamida em condições não desnaturantes neste último, revelou a presença de isoformas na fonte de carbono farinha de banana. Os resultados obtidos revelaram que M. phaseolina se mostra eficiente na expressão de amilases em fontes de carbono alternativas.

PALAVRAS-CHAVES: Enzimologia, Fungos filamentosos, Diastases.

ABSTRACT: Amylases are a group of enzymes which act upon starch liberating several products including dextrines. Progressively, small polymers made of glycose units are also liberated (GUPTA, et al., 2003). They are of important biotechnological application chiefly in the pharmaceutical, textile, detergent and food industries. Amylolitical enzymes are produced by bacteria, yeast and fungi. The most commonly used amylolitical enzymes are the ones produced by filamentous fungi, notably those from the Aspergillus and Rhizopus genera (PANDEY, et al., 1999 and PANDEY, et al., 2005). Macrophomina phaseolina belongs to the Fungi kingdom, Phylum Ascomomycota, class Ascomycetes genus Macrophomina (GALL, et al., 1980). The Macrophomina phaseolina fungus is a fitopatogenic agent that causes the common bacterial blight and is thus considered to be the one of the main pathogens of bean seeds (CHIBA, et al., 2000). On the other hand, the fact that it is a producer of enzymes of 
biotechnological interest is largely unknown, making it difficult to assess the possible benefits this fungus might bring to several industrial sectors.

This paper aims at evaluating the production of amylases by the fungus Macrophomina phaseolina in conventional and non conventional carbon sources and, above all, at assessing the potential of M.phaseolina to produce enzymes of biotechnological interest, thus offering another use of fungi in the production of molecules of interest to the industry. Results show good specific activities of amylases with dextrinizing and saccarifiying activities in carbon sources such as starch, rice flour and jackfruit seed flour. The total protein profiles in polyacrilamide gel were analyzed, as well as amylolitical activity in polyacrilamide gel in nondenaturant conditions; in the latter, isophorms were found in the protein source banana flour. Obtained results show that M. phaseolina is efficient in obtaining expression of amylases from alternative carbon sources.

KEY WORDS: Enzymolgy, diastase, filamentous fungi

\section{INTRODUÇÃO}

Amilases são responsáveis pela degradação da molécula de amido e estão amplamente distribuídas na natureza. $\mathrm{O}$ amido é encontrado principalmente em sementes de cereais como milho, cevada, trigo e arroz e em tubérculos ou raízes como batata e mandioca cujo tamanho e forma dos grãos são específicos para os distintos cereais (MORAES, 2004). O amido é o mais importante polissacarídeo de reserva do reino vegetal. Possui em sua constituição amilose (25\%) e amilopectina (75\%). Amilose é um polímero linear constituído de cerca de 6000 resíduos de glicose unidos por ligações glicosídicas do tipo $\alpha-1,4$. Amilopectina consiste de pequenas cadeias laterais de 15 a 45 resíduos unidos por ligações do tipo $\alpha-1,6$ (BULÉON, et al., 1998).

Segundo GUPTA (2003), as amilases são divididas em dois grupos, as endoamilases e exoamilases. As endoamilases catalisam hidrólises de forma aleatória no interior da molécula do amido. Essa ação causa a formação de ramos lineares de oligossacarídeos de cadeias de vários comprimentos e dessa forma quebram as ligações glicosídicas $\alpha-1,4$ presentes na parte interna (endo) das cadeias de amilose ou amilopectina. A $\alpha$-amilase (E.C. 3.2.1.1) é a endoamilase mais conhecida. As exoamilases hidrolisam exclusivamente ligações glicosídicas $\alpha-1,4$, como a $\beta$-amilase (E.C. 3.2.1.2) ou ambas as ligações $\alpha-1,4$ e $\alpha-1,6$, como amiloglicosidase (E.C. 3.2.1.3) e glicosidase (E.C. 3.2.1.20). Outros exemplos de exoamilases são a ciclodextrina glicosiltransferase (E.C. 2.4.1.19) e a $\alpha$-amilase maltogênica (glicano 1,4- $\alpha$-glicanohidrolase, E.C. 3.2.1.133).

MORAIS (2004) relata além das endo e exoamilases mais dois grupos de amilases, as amilases desramificadoras e as transferases. As enzimas desramificadoras consistem em um terceiro grupo de enzimas conversoras do amido. Essas enzimas atuam diferentemente na pululana. São enzimas que hidrolisam somente ligações $\alpha-1,6$ sendo que as isoamilases (E.C. 3.2.1.68) hidrolisam apenas amilopectina resultando em polissacarídeos lineares de cadeia longa, e as pululanases tipo I (E.C. 3.2.1.41) hidrolisam as ligações $\alpha-1,6 \mathrm{em}$ pululana e amilopectina. Um grupo de especial de Pululanases são as denominadas pululanases do tipo II, que hidrolisam ligações tanto do tipo $\alpha-1,4$ quanto $\alpha-1,6$ e são denominadas $\alpha$-amilase-pululanase ou amilopululanase sendo os produtos de hidrólise a maltose e a maltotriose. Dessa forma, essas são as formas diferenciadas de hidrolisar a pululana.Transferases constituem um quarto grupo de enzimas conversoras ou modificadoras de amido. As transferases quebram ligações glicosídicas $\alpha-1,4$ da molécula doadora e transferem parte do doador para um aceptor glicosídico com a formação de uma nova ligação glicosídica. Enzimas como amilomaltase (EC 2.4.1.25) e ciclodextrina glicosiltransferase (EC 2.4.1.19) formam uma nova ligação $\alpha-1,4$ e ao mesmo tempo liga a extremidade redutora à não redutora. Essas enzimas são muito utilizadas nas indústrias cosméticas, farmacêuticas e de alimentos (TACHIBANA, 1999). Amilomaltases são similares as ciclodextrinas glicosiltransferases em relação ao tipo de reação enzimática, porém, amilomaltases produzem um produto linear diferente do produto formado pelas ciclodextrinas glicosiltransferases que produzem um produto cíclico. Amilomaltases foram encontradas em diferentes microrganismos estando envolvidas na utilização de maltose ou degradação de glicogênio dos mesmos.

Amilases apresentam grande importância biotecnológica tais como aplicações nas indústrias têxteis, papel e celulose, de couro, detergentes, cervejas, bebidas destiladas, panificação, cereais para alimentação infantil, liquefação e sacarificação do amido, ração animal, indústria química e farmacêutica. Apesar de poderem ser derivadas de diversas fontes, incluindo plantas, animais e microrganismos, enzimas microbianas geralmente encontram grande demanda industrial. Atualmente, grandes quantidades de amilases microbianas estão disponíveis comercialmente e têm aplicação quase completa na hidrólise do amido em indústrias de processamento do amido (GUPTA, et al., 2003; PANDEY, et al., 2005).

Macrophomina phaseolina pertence ao reino Fungi, Phylum Ascomomycota, classe Ascomycetes gênero Macrophomina. Forma picnídios escuros, não estromáticos, medindo 120 a 150 micra de diâmetro; os conídios são elípticos, hialinos, alongados, unicelulares, com membrana espessa, medindo em média $23 \times 10$ micra. É um fungo extremamente polífago, tendo sido constatado em mais de 200 plantas hospedeiras, o que explica sua ampla distribuição geográfica. Sobrevive de um ano para outro em seus hospedeiros ou em restos de cultura, 
favorecido pela sua capacidade saprófita e pela formação de escleródios, os quais podem permanecer viáveis no solo por mais de um ano (GALL, et al., 1980). O fungo Macrophomina phaseolina, agente causal da podridão cinzenta do caule, é considerado, pelos danos causados, um dos principais patógenos de sementes de feijão. A fonte de inóculo primária é constituída pela semente infectada, restos de cultura colonizada pelo micélio do fungo e escleródios (CHIBA, et al., 2000).

O mercado mundial da tecnologia enzimática movimenta, anualmente, cerca de dois bilhões de dólares (NORDISK, 1996). Resíduos provenientes da indústria de alimentos envolvem quantidades apreciáveis de cascas, farinhas, caroços e outros. Esses resíduos são fontes baratas e são utilizadas como substrato ou fonte de carbono no processo fermentativo para obtenção de compostos de interesse industrial. Tal montante justifica-se pelo interesse gerado por processos que envolvem tecnologia de baixo custo energético, com menor impacto ambiental e que utiliza matérias primas renováveis, adequando-se ao reaproveitamento de subprodutos da agroindústria (COELHO, 2001). Soma-se a isso a importância do conhecimento de novas espécies de microrganismos produtoras de enzimas com potencial interesse biotecnológico.

Este trabalho teve como objetivo avaliar fontes de carbono convencionais na indução de amilases como o amido e fontes não convencionais como farinha de banana, farinha de arroz, casca de soja, farinha de milho e semente de farinha de semente de jaca pelo fungo M.phaseolina.

\section{MATERIAIS E MÉTODOS}

\section{Utilização e Manutenção do isolado M. phaseolina}

$O$ isolado utilizado neste trabalho foi da Coleção do Laboratório de Enzimologia da Universidade Federal de Goiás (DCIF/ICB) obtido pela EMBRAPA Arroz-Feijão. Macrophomina phaseolina foi mantida com repiques periódicos em placas de Petri, contendo meio MYG $(0,5 \%$ de extrato de malte, $0,25 \%$ de extrato de levedura, $1 \%$ de glicose e $2 \%$ de ágar) e estocada a $4^{\circ} \mathrm{C}$.

\section{Produção de amilases em meio líquido}

10 discos de $4 \mathrm{~mm}$ de diâmetro do miscélio de M.phaseolina foram inoculados em frascos de $250 \mathrm{~mL}$ contendo $100 \mathrm{~mL}$ de meio TLE $\left\{\mathrm{CaCl}_{2} 0,1 \mathrm{~g} \mathrm{~L}^{-1}, \mathrm{KH}_{2} \mathrm{PO}_{4} 7,0 \mathrm{~g} \mathrm{~L}^{-1}, \mathrm{~K}_{2} \mathrm{HPO}_{4} 2,0 \mathrm{~g} \mathrm{~L}^{-1},\left(\mathrm{NH}_{4}\right)_{2} \mathrm{SO}_{4} 0,1 \mathrm{~g} \mathrm{~L}^{-1}\right.$, $\mathrm{MgSO}_{4} .7 \mathrm{H}_{2} \mathrm{O} 0,1 \mathrm{~g} \mathrm{~L}^{-1}$ e $0,1 \mathrm{~mL}$ de solução elementos traços\} contendo uma das seguintes fontes de carbono (p/v): amido (1\%), milho moído (1\%), Farelo de arroz moído (1\%), Farelo de banana (1\%), Casca de soja $(1 \%)$, semente de jaca moída (1\%). Os frascos foram incubados em agitador rotatório à $28^{\circ} \mathrm{C}$ e velocidade de $160 \mathrm{rpm}$. Após 24, 48, 72 e 96 horas de incubação alíquotas de $20 \mathrm{~mL}$ foram coletadas, centrifugadas, dialisadas e armazenadas a $-20^{\circ} \mathrm{C}$ e utilizadas na dosagem da atividade de amilases.

\section{Determinação da atividade amilolítica}

A atividade amilolítica foi determinada por dois métodos diferentes, utilizando amido como substrato. O primeiro denominado de atividade dextrinizante, baseia-se na variação da intensidade da cor do complexo iodoamido (FUWA, 1954). O segundo denominado de método sacarificante, baseia-se na produção de açúcares redutores (MILLER, 1959).

\section{Atividade amilolítica dextrinizante}

A $80 \mu \mathrm{l}$ de tampão acetato de sódio (50 mmol. $\mathrm{L}^{-1}, \mathrm{pH} 5$,5), foram adicionados $20 \mu \mathrm{l}$ de amostra enzimática e $100 \mu \mathrm{l}$ de solução de amido $(0,5 \%)$. A mistura foi incubada a $50^{\circ} \mathrm{C}$ por 20 minutos e a reação interrompida com a adição de $200 \mu \mathrm{l}$ de ácido acético $\left(1,0 \mathrm{~mol}^{\mathrm{L}} \mathrm{L}^{-1}\right)$ e $200 \mu \mathrm{l}$ da solução de iodo/iodeto $(1 \%$ iodo em etanol absoluto, $10 \%$ iodeto de potássio e água destilada na proporção de $1 \mathrm{v}: 1 \mathrm{v}: 3 \mathrm{v})$. O volume foi completado para $10 \mathrm{~mL}$ com água destilada, homogeneizado e a absorbância determinada a $660 \mathrm{~nm}$. A quantidade de amido consumido é calculada de acordo com uma curva padrão construída com quantidades crescentes de amido solúvel $\left(0-0,5 \mathrm{mg}^{-1} \mathrm{~m}^{-1}\right)$. Uma unidade $(U)$ de atividade amilolítica dextrinizante foi definida como sendo a quantidade de enzima necessária para hidrolisar 0,1mg de amido por minuto de reação (FUWA, 1954).

\section{Atividade amilolítica sacarificante}

A $80 \mu \mathrm{l}$ de tampão acetato de sódio $\left(50 \mathrm{mmol} . \mathrm{L}^{-1}, \mathrm{pH} 5,5\right)$, foram adicionados $20 \mu \mathrm{l}$ de amostra enzimática e $100 \mu$ l de solução de amido $(0,5 \%)$. A mistura foi incubada a $50^{\circ} \mathrm{C}$ por aproximadamente 12 horas. Após este tempo, $100 \mu \mathrm{L}$ da mistura de reação foram coletadas e adicionadas em tubo de ensaio contendo $1,0 \mathrm{~mL}$ do reagente ácido dinitrosalicilico $\left\{10 \mathrm{~g} . \mathrm{L}^{-1}\right.$ ácido dinitrosalicilico (DNS), $100 \mathrm{~mL}$ de NaOH $\left(2 \mathrm{mmol} . \mathrm{L}^{-1}\right), 300 \mathrm{~g} \cdot \mathrm{L}^{-1} \mathrm{de}$ tartarato de sódio e potássio\}. A mistura foi fervida por 5 minutos em banho-maria a $96^{\circ} \mathrm{C}$ e a absorbância determinada a $550 \mathrm{~nm}$. A quantidade de áçúcares redutores formados é calculada de acordo com uma curva padrão de glicose (MILLER, 1959). Uma unidade (U) de atividade sacarificante foi definida como a quantidade de enzima que libera $0,1 \mathrm{mg}$ de açúcar redutor por minuto de reação. 


\section{Determinação de proteínas}

A concentração de proteínas foi determinada pelo método descrito por Bradford (1976) utilizando-se albumina sérica bovina (Sigma) como padrão. A Reação foi conduzida pela adição de $100 \mu \mathrm{l}$ de amostra e $1 \mathrm{ml}$ do reagente de Bradford e incubado a temperatura ambiente por 15 minutos. A leitura foi feita em espectrofotômetro a $595 \mathrm{~nm}$.

\section{Eletroforese desnaturante (SDS-PAGE).}

A análise do perfil de proteínas secretadas pelo isolado foi analisado utilizando o sistema de eletroforese (MiniGel-Sigma) em gel de poliacrilamida (12\%) em condições desnaturantes conforme descrito por Laemmli (1970). As amostras foram concentradas por liofilização. As amostras concentradas foram ressuspendidas em tampão de amostra $1 \mathrm{X}\left(50 \mu \mathrm{L}\right.$ de tampão Tris- $\mathrm{HCl} 0,5 \mathrm{mmol} \mathrm{L}^{-1} \mathrm{pH}$ 6,8, $1,0 \mu \mathrm{L} \beta-$ mercaptoetanol, $100 \mu \mathrm{L}$ SDS $10 \%, 100 \mu \mathrm{L}$ glicerol, $0,005 \mathrm{mg}$ de azul de bromofenol e água destilada suficiente para 1,0 mL), fervidas por 5 minutos e aplicadas no gel.

A corrida foi feita utilizando-se uma voltagem inicial de $80 \mathrm{~V}$, posteriormente aumentada para $100 \mathrm{~V}$. Os marcadores utilizados para a determinação da massa molecular foram: $\beta$-galactosidase $(116,0 \mathrm{kDa})$, albumina sérica $(66,2 \mathrm{kDa})$, ovoalbumina $(45 \mathrm{kDa})$, Lactato desidrogenase $(35,0 \mathrm{kDa})$, REase Bsp98I (25,0 kDa), $\beta$ lactoglobulina $(18,4 \mathrm{kDa})$, Lisozima $(14,4 \mathrm{kDa})$.

\section{Técnica de coloração do gel por prata}

Após a corrida, o gel foi corado para proteínas utilizando-se o método descrito por Blum et al. (1987). Os géis foram incubados em solução fixadora (50\% metanol e $12 \%$ ácido acético glacial) por duas horas, e lavados três vezes com uma solução de etanol $50 \%$ (v/v) durante 20 minutos. Em seguida, foram incubados durante 1 minuto em uma solução de $0,02 \%$ tiossulfato de sódio, lavados rapidamente três vezes com água destilada e transferidos para uma solução de $0,2 \%$ nitrato de prata, contendo $75 \mu \mathrm{l}$ de formaldeído (37\%). Após 20 minutos foram lavados três vezes com água destilada e incubados na solução reveladora ( $6 \%$ carbonato de sódio, $0,05 \%$ formaldeído e $2 \%$ tiossulfato de sódio), até a visualização das bandas de proteína. A reação foi interrompida por incubação dos géis na solução fixadora (50\% metanol e 12\% ácido acético) por 20 minutos.

\section{Determinação da atividade amilolítica em gel de poliacrilamida}

Para determinação de atividade em gel de poliacrilamida (12\%) as condições de corrida do gel foram as mesmas descritas para a técnica de eletroforese desnaturante (SDS-PAGE), exceto para o tampão de amostra que não continha $\beta$-mercaptoetanol e a corrida foi realizada a $4^{\circ} \mathrm{C}$. Após a corrida, o gel foi incubado com tampão acetato de sódio (50 mmol. $\left.\mathrm{L}^{-1}, \mathrm{pH} 5.5\right)$ por uma hora. Em seguida, o gel foi transferido para um recipiente contendo uma solução de amido $(0,5 \%)$ e incubado por 12 horas a $4^{\circ} \mathrm{C}$. Após esse período, o gel foi incubado por duas horas a temperatura de $37^{\circ} \mathrm{C}$ e coberto com uma solução de iodo-iodeto para visualização das bandas de degradação do amido (LACKS \& SPRINGHORN, 1980).

\section{RESULTADOS E DISCUSSÃO}

A avaliação das fontes de carbono revelou que todas foram hábeis na produção de amilases tanto com atividades dextrinizantes quanto com atividades sacarificantes. A atividade específica foi calculada dividindo as unidades de atividade encontradas por $\mathrm{mL}$ de meio pela quantidade em $\mathrm{mg}$ de proteínas por $\mathrm{mL}$ de meio $(\mathrm{U} / \mathrm{mg}$ de proteína). A figura 1 mostra a determinação de proteínas totais produzidas nas fontes de carbono testadas. A fonte de carbono amido foi a que apresentou melhores atividades específicas tanto como dextrinizante quanto como sacarificante (figuras 2 e 3). Algumas linhagens de microrganismos são capazes de produzir tanto $\alpha$-amilases como glicoamilases. Esse fato é observado em linhagens de Aspergilus niger (MORAIS, 2004). As atividades específicas dextrinizantes e sacarificantes mais elevadas foram detectadas nos tempos de 24 e 48 horas com diminuição dessas atividades nos tempos de 72 e 96 horas. Uma explicação para esse fato é que no meio de indução não houve a adição de glicose. A glicose é uma fonte de carbono facilmente metabolizável e esse fato pode fazer com que o microrganismo consuma primeiramente a glicose como fonte de carbono sem que haja a necessidade de expressão de enzimas específicas e, posteriormente, com o esgotamento dessa fonte o microrganismo sente a necessidade de expressar enzimas específicas para que possa metabolizar outra fonte de carbono presente no meio. Provavelmente a expressão inicial de amilases em fonte de carbono amido juntamente com glicose poderia ocorrer posteriormente (MONTEIRO \& ULHOA, 2006). A alta densidade celular e alta taxa de crescimento específico podem ser obtidas com glicose, mas alta atividade específica e produção de enzima são obtidas com amido (PANDEY, 2000). 


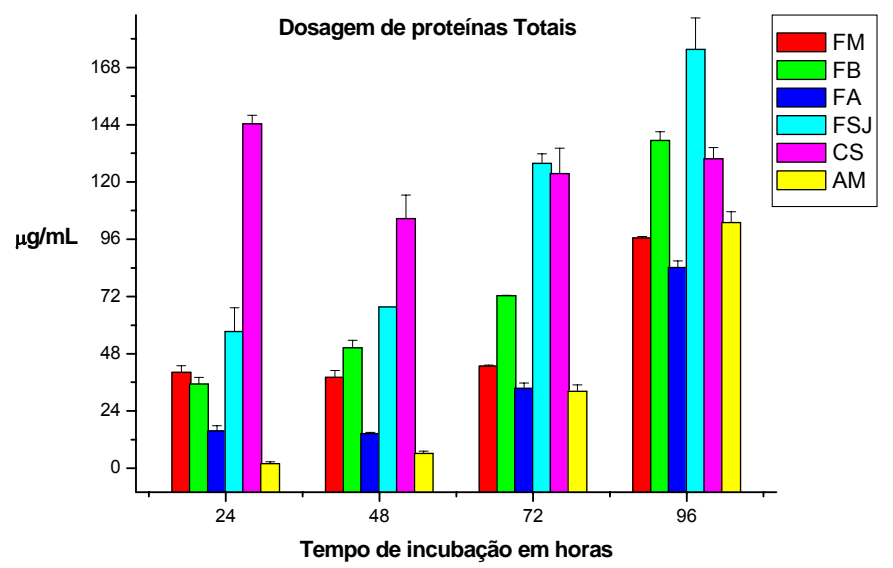

Figura 1-Dosagem de proteínas totais pelo método de Bradford (1976) das fontes de carbono: FM) Farinha de milho; FB) Farinha de Banana; FA) Farinha de arroz; FSJ) Farinha de semente de Jaca; CS) Casca de soja; AM) Amido.

A fonte de carbono farinha de arroz foi, depois de amido, uma boa fonte de indução de amilases com atividade sacarificante (figura 3). A atividade sacarificante foi determinada pelo método de ADNS (MILLER, 1959), portanto, a atividade amilolítica foi determinada por um método que determina açúcares redutores produzidos na hidrólise do amido. Este tipo de medida não possibilita identificar quais tipos de amilases foram produzidos pelo microrganismo. Dessa forma, um experimento foi realizado para quantificar a liberação de glicose a partir da hidrólise do amido utilizando o Kit Glucox 500 (Doles reagentes) obtendo valores de 1,18 $\mathrm{mg} / \mathrm{mL}$ para a fonte amido e $1,56 \mathrm{mg} / \mathrm{mL}$ para fonte farinha de arroz, sugerindo a possível presença de glicoamilases. A presença desse tipo de amilases só se confirma através de técnicas de fracionamento protéico e posterior análise em cromatografia de camada delgada dos produtos de hidrólise do amido da proteína pura.

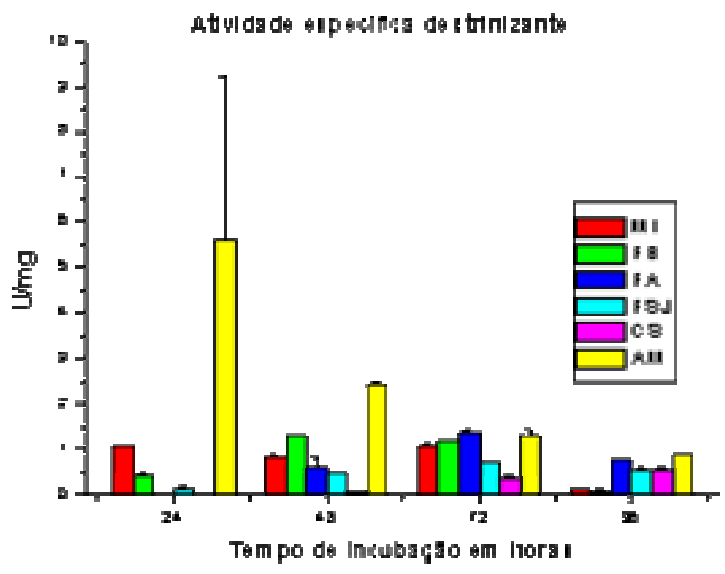

Figura 2

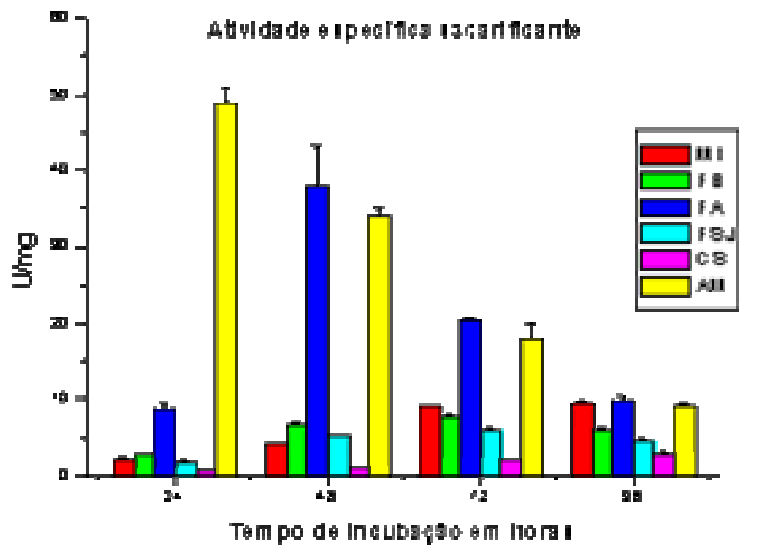

Figura 3

Figuras 2 e 3-Atividades específicas dextrinizante e sacarificante de amilases produzidas por M.phaseolina. Fontes de carbono: (MI) Farinha de milho. (FB) Farinha de banana. (FA) Farinha de arroz. (FSJ) Farinha de semente de jaca. (CS) Casca de soja. (AM) Amido.

O perfil de proteínas totais foi analisado em géis de poliacrilamida (figuras 4,5 e 6 ). A análise em gel de poliacrilamida possibilita analisar a heterogeneidade protéica ou ainda o grau de pureza de uma preparação. Esse 
método permite as estratégias possíveis para etapas de purificação e dessa forma, quanto menor a quantidade de proteínas observadas em géis de poliacrilamida, possivelmente menor serão as etapas de purificação obtendo um ganho no rendimento de purificação e diminuição das perdas de frações protéicas observadas durantes várias etapas de purificação. Em algumas terapias há a necessidade da utilização de enzimas com alto grau de pureza (MORAIS, 2004). Por outro lado em certas terapias não há a necessidade de graus de pureza elevados como é o caso de medicamentos que auxiliam a digestão. Nesses medicamentos, amilases atuam como aditivos da digestão em casos onde há redução parcial ou total de enzimas líticas envolvidas no processo de digestão. Esses medicamentos são administrados via oral e sua administração não tem mostrado toxicidade em relação ao grau de pureza dessas enzimas que são utilizadas nessas terapias, de forma parcialmente puras. (Said \& Pietro, 2004).

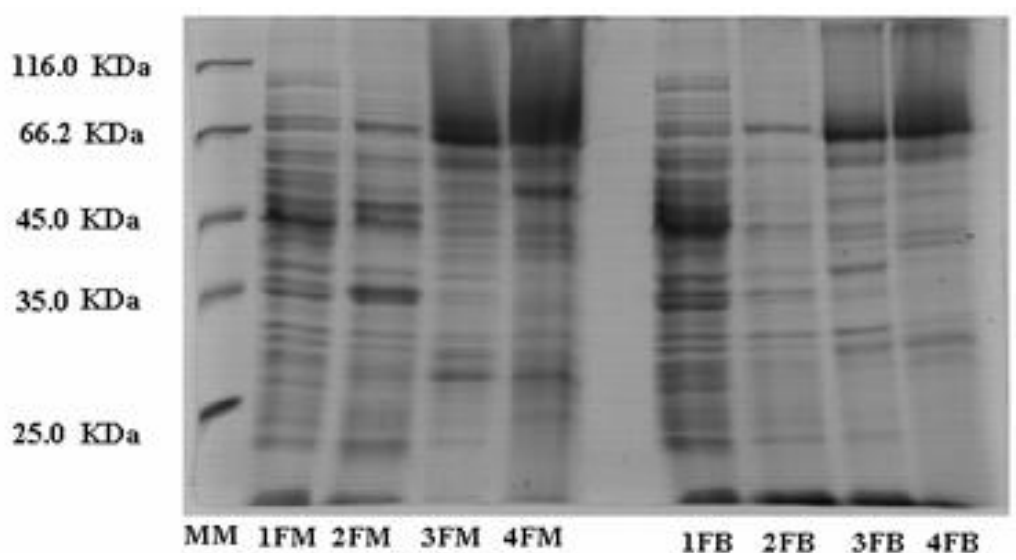

Figura 4-Perfil de proteínas por M.phaseolina. MM) Marcador de massa Molecular. 1FM) Farinha de milho 24 horas de indução. 2FM) Farinha de milho 48 horas de indução.3FM) Farinha de milho 72 horas de indução. 4FM) Farinha de milho 96 horas de indução. 1FB) Farinha de banana 24 horas de indução. 2FB) Farinha de banana 48 horas de indução. 3FB) Farinha de banana 72 horas de indução. 4FB) Farinha de banana 96 horas de indução.

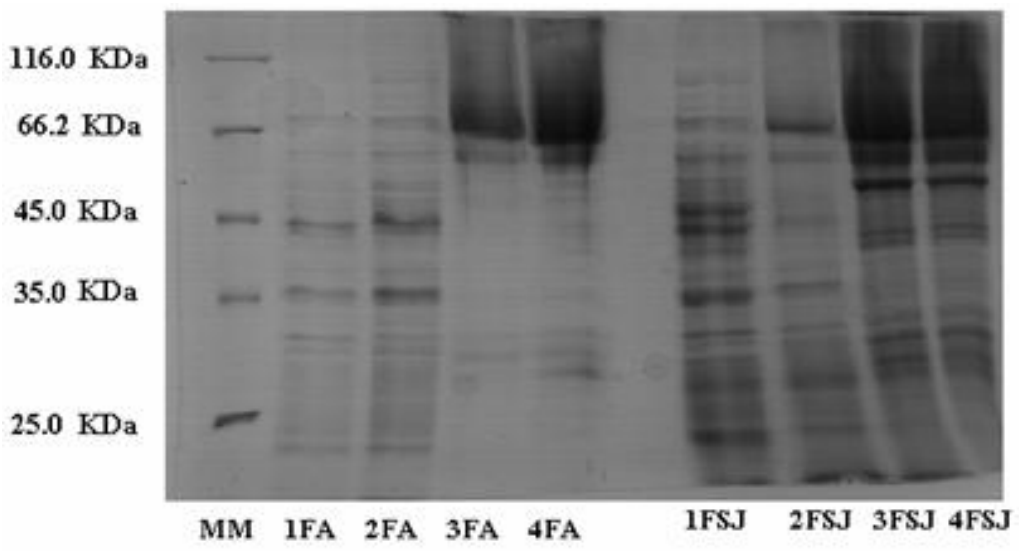

Figura 5-Perfil de proteínas por M.phaseolina. MM) Marcador de massa Molecular. 1FA) Farinha de arroz 24 horas de indução. 2FA) Farinha de arroz 48 horas de indução.3FA) Farinha de arroz 72 horas de indução. 4FA) Farinha de arroz 96 horas de indução. 1FSJ) Farinha de semente de jaca 24 horas de indução. 2 FSJ) Farinha de semente de jaca 48 horas de indução. 3 FSJ) Farinha de semente de jaca 72 horas de indução. 4 FSJ) Farinha de semente de jaca 96 horas de indução.

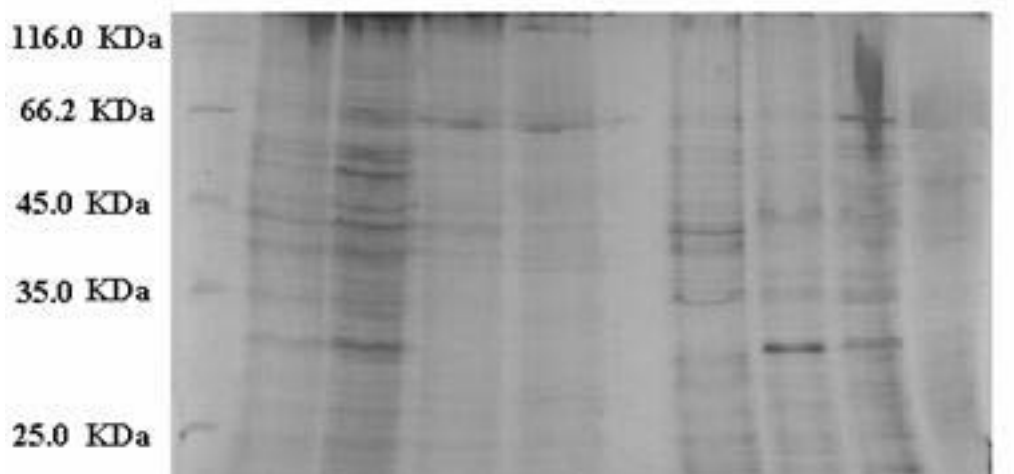


Figura 6-Perfil de proteínas por M.phaseolina. MM) Marcador de massa Molecular. 1CS) Casca de soja 24 horas de indução. 2 CS) Casca de soja 48 horas de indução.3 CS) Casca de soja 72 horas de indução. 4 CS) Casca de soja 96 horas de indução. 1A) Amido 24 horas de indução. 2 A) Amido 48 horas de indução. 3 A) Amido 72 horas de indução. 4 A) Amido 96 horas de indução.

Ao avaliar a atividade amilolítica em gel (figura 7) pode-se observar que com exceção das fontes farinha de arroz e casca de soja todas as fontes foram hábeis na degradação do amido presente no gel de poliacrilamida. Nota-se, porém que amido e farinha de semente de jaca apresentam maior atividade amilolítica em gel. Quando se compara com o gráfico da atividade específica, observa que farinha de semente de jaca apresenta uma discreta atividade dextrinizante quando comparada com a boa atividade amilolítica em gel. A atividade específica é a relação entre proteínas totais presentes num extrato enzimático versus a atividade da enzima então, quanto maior a quantidade de proteínas presente menor será a atividade específica e vice versa. A fonte farinha de semente de jaca apresenta um perfil protéico com várias bandas de proteínas (figura 3) e esse fato pode ser a explicação de que apesar de apresentar menor atividade específica em relação às outras fontes analisadas, a análise da atividade amilolítica em gel (figura 7) revela que a quantidade de enzima presente é eficiente na degradação do amido. Outro fato de interesse na análise da atividade amilolítica em gel de poliacrilamida foi o aparecimento de uma outra banda mais fraca logo abaixo da banda mais forte na fonte farinha de banana, esse fato pode evidenciar a presença de isoenzimas (figura 7). Isoenzimas são formas múltiplas de uma mesma enzima com afinidade individual para um mesmo substrato. As isoenzimas são controladas geneticamente por alelos ou por genes situados em diferentes locos (SCANDALIOS, 1969; MARKET, 1975). Fato interessante para estudos posteriores para caracterização individual dessas formas enzimáticas.

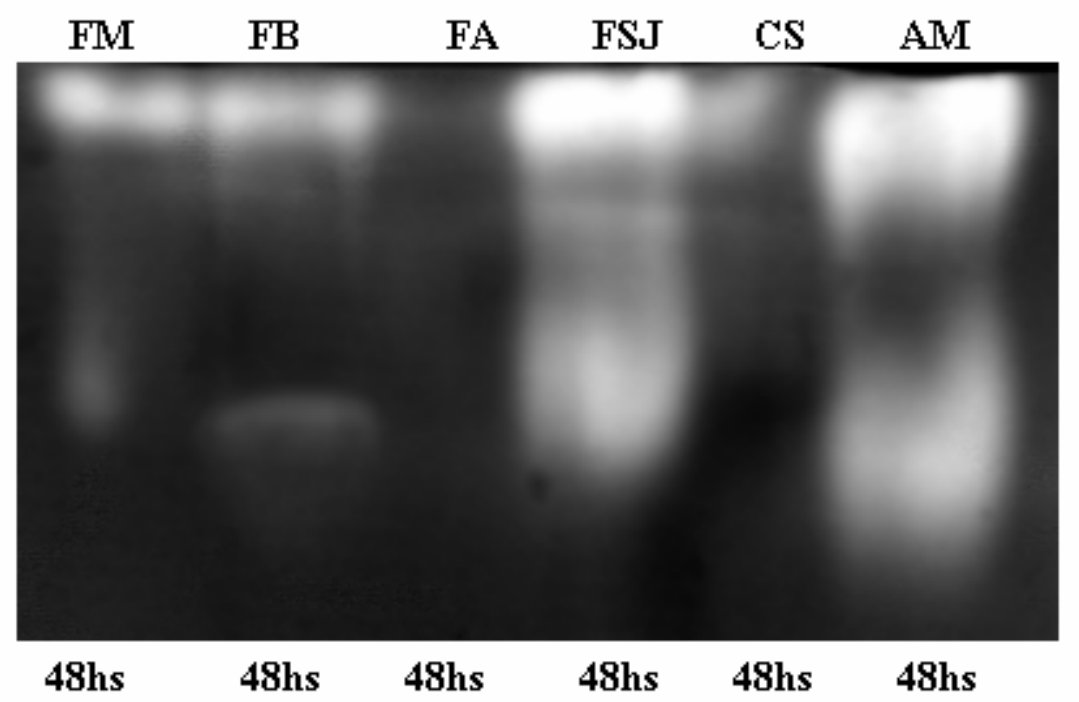

Figura 7-Atividade amilolítica em gel de poliacrilamida. M) Farelo de milho. FB) Farinha de banana. FA) Farinha de arroz. FJ) Farinha de semente de jaca. FS) Casca de soja. A) Amido.

\section{CONCLUSÕES}

As fontes de carbono avaliadas nesse trabalho foram capazes de induzir amilases. Entretanto, algumas foram mais eficazes na expressão de amilases pelo fungo Macrophomina phaseolina, entre as quais se destacam as fontes amido e farinha de arroz.

Amido foi a fonte de carbono mais eficiente na indução de amilases tanto com atividades dextrinizantes quanto sacarificantes. Farinha de arroz foi mais eficaz na indução de amilases com atividade sacarificantes possivelmente glicoamilases pelos resultados obtidos da determinação de glicose por método específico. 
Observou-se que o perfil protéico apresentou uma variedade de proteínas totais nas fontes de carbono avaliadas possibilitando a melhor estratégia de purificação. Dessa forma, fontes de carbono que induzem poucas proteínas totais aliadas à alta atividade enzimática são mais atraentes para tal fim. Dentre as fontes que mais se destacaram em atividades dextrinizantes e sacarificantes, amido e farinha de arroz, foi observado que estas apresentam poucas proteínas totais em relação às outras fontes analisadas. Esse fato é muito importante, pois a escolha de substratos capazes de induzir enzimas de interesse biotecnológico devem ser de preferência baratos e de fácil obtenção como o amido ou mesmo a de subprodutos como a farinha de arroz.

A análise da atividade amilolítica em gel de poliacrilamida mostrou que farinha de semente de jaca apresentou juntamente com amido boa atividade amilolítica e que farinha de banana apresenta isoformas.

O fungo Macrophomina phaseolina é um fitopatógeno que causa a podridão cinzenta em feijão e por isso é muito estudado sob esse aspecto. Outro aspecto, ou seja, a produção de enzimas com potencial biotecnológico foi também o objeto de estudo desse trabalho. As análises mostraram que apesar de causar prejuízos em lavouras, o fungo M.phaseolina se mostrou eficaz na expressão de amilases e outras enzimas com potencial biotecnológico que podem ser utilizadas em indústria farmacêutica, detergente têxtil e alimentícia, entre outras.

A realização desse trabalho resultou em outros questionamentos como a influência da glicose na regulação da expressão de proteínas, a purificação de amilases das fontes que mais se destacaram e consequentemente sua características e classificação, a possibilidade de se expressar essas enzimas em outros microrganismos resultando em trabalhos de expressão heteróloga e, sobretudo, estudos moleculares desse fungo com relação aos genes envolvidos na expressão de proteínas de interesse.

\section{REFERÊNCIAS BIBLIOGRÁFICAS}

BLUM, H.; BEIER, H.; GROSS, H. Improvised silver staining of plant proteins, RNA and DNA in polyacrilamide gels. Electrophoresis. v. 8, p. 93-99, 1987.

BRADFORD, M.M. A rapid and sensitive method for the quantification of microgram quantitites of protein utilizing the principle of protein-dye binding. Anal. Biochem. v.72, p.248-254, 1976.

BULÉON, A.; et al. Starch granules: structure and biosintesis. Internacional journal of Biological Macromolecules. v. 23, p. 85-112, 1998.

CHIBA, E.Y.K.S.; VECHIATO, M.H.; LASCA, C.C. Efeito do tratamento de sementes de feijão (Phaseolus vulgaris) com fungicidas no controle de Macrophomina phaseolina e na emergência de plântulas. Arquivos Instituto Biológico. v. 69, n.1, 2000.

COELHO; et al. Aproveitamento de resíduos agroindustriais: Produção de enzimas a partir da casca de coco verde. Boletim CEPPA. v. 19, p.33-42, 2001.

FUWA, $\mathrm{H}$. A new method for microdetermination of amylase activity by the use of amylose as the substrate. The journal of Biochimistry. v. 41, p. 583-603, 1954.

GALL; et al. Manual de fitopatologia: Doenças das plantas cultivadas. São Paulo: Agronômica Ceres, 1980.

GUPTA, R; MOHAPATRA, H; GOSWAMI, V.K.; CHAUHAN, B. Microbial a-Amylases: Biotechnological Perspective. Process Biochemistry. jan. 2003, p. 1.

LACKS,S.A.; SPRINGHORN, S.S. Renaturation of enzymes after polyacrilamide gel eletrophoresis in the presence of sodium dodecyl sulfate. The Journal of Biological Chemistry. v. 255, p.7467-7473, 1980.

LAEMMLI, U.K. Cleavage of structural proteins assembly of the head of bacteriophage $T_{4}$. Nature. v. 227, p. 680$685,1970$.

MARKERT, C.L. Biology of isozymes. In: MARKERT, C.L, Isozymes. New York, Academic Press. p.1-9, 1975.

MILLER, G.L. Use of dinitosalicylic acid reagent for the determination of reducing sugar. Analytical Chemistry. v. 31, p. 426-428, 1959.

MONTEIRO, V.N.; ULHOA, C.J. Biochemical Characterization of a $\beta-1,3$ Glucanase from Trichoderma koningii Induced by Cell Wall of Rhizoctonia solani. Current Microbiology. v. 52, p. 92-96, 2006. 
MORAES, L.M.P. Amilases. In: SAID, S.; PIETRO, R. Enzimas como agentes Biotecnológicos. Ribeirão Preto: Legis Summa, 2004.

NORDISK S/A. Biotimes. [S.I.] 1996.

PANDEY; et al. Solid State Fermentation for the Production of Industrial Enzymes. Current Science. v.77, p. 149161, 1999.

PANDEY; et al. Enzyme Technology. $1^{\text {a }}$ ed. New Delhi: Asiatech Publishers, Inc, 2005.

PANDEY, A.; et.al. Advances in microbial amylases. Biotechnology and Applied Biochemistry. v. 31, p. 135-152. 2000.

TACHIBANA,Y.; et al. Purification and Characterization of an Extremely Thermostable Cyclomaltodextrin Glucanotransferase from a Newly isolated Hyperthermophhilic Archaeon, a Thermococcus sp. Applied and Environmental Microbiology. v. 65, p. 1991-1997, 1999.

SAID, S.; PIETRO, R.C.L.R. Enzimas nas Ciências Farmacêuticas In: SAID, S.; PIETRO, R.C.L.R. Enzimas como agentes Biotecnológicos. Ribeirão Preto: Legis Summa, 2004.

SCANDALIOS, J.G. Genetic control of multiple molecular forms of enzymes in plants; a review. Biochem. Genet. v. 3, p. 37-79, 1969. 